\title{
Influence of noise on the accuracy of measuring image shifts based on optical correlator
}

\author{
${ }^{1,2}$ Fan Chao \\ ${ }^{1}$ College of Information Science and Engineering of Henan University of \\ Technology, Zheng Zhou, 450001, China \\ ${ }^{2}$ Key Laboratory of the Grain Information Processing and Control of the Ministry of \\ Education of China, Zheng Zhou, China
}

Received: 30.08 .2017

\begin{abstract}
To measure shifts of images taken by a space camera in real time with high resolution, we suggest a joint transform correlator (JTC). Since, in accordance with operation principles, the signal-to-noise ratio is very low for input JTC images, it is necessary to study the influence of noises on the accuracy of shift measurements. First we explain the principles of measuring the image shifts based on the JTC. Then a white background Gaussian noise and a pattern noise with different variances are added to the input JTC images, and the accuracy of measuring the shifts is simulated for five different processing methods. Finally, we build the experimental platform to implement our technique and study the performance of the image-shift measurements under the conditions when both the background and pattern noises are added together. The simulation and experimental results testify that the measurement accuracy typical for the method of powerspectrum subtraction and binarization with zero threshold is superior if compared with the other four processing methods considered by us. In particular, the corresponding measurement error is less than 0.12 pel even for the input images characterized by the signal-to-noise ratio $1 \mathrm{~dB}$. This meets perfectly typical operating requirements to space cameras.
\end{abstract}

Keywords: joint transform correlators, space cameras, image shifts, noise

PACS: $42.79 . \mathrm{Hp}$

UDC: 004.932

\section{Introduction}

To make remote sensing cameras lightweight and miniature, time-delay and CCD-integration techniques are often used inside image sensors of the cameras. The principle of such CCDs is based on push-broom imaging. Then image motion and travelling of a charge packet in the focal plane must be synchronized. Any asynchronization called usually as an 'image shift' would deteriorate the quality of images taken by a given camera [1].

A number of factors that act during imaging, e.g. changes in the attitude of satellite, variations in the velocity-height ratio, rotation of Earth or jitter of platform, can cause extra image shifts in the focal plane that destroy the synchronism [2, 3]. Although these shifts are often small, the accumulated shifts cannot be ignored with increasing integral number and focal length of the camera. They reduce camera resolution and cause image obscuring. For decreasing image shifts, stability of satellite is usually controlled by all kinds of technologies, thus increasing heavily the cost and enlarging the size and weight of the satellite $[4,5]$.

To solve this problem, joint transform correlators (JTCs) can be used for measuring the image shifts on satellites in real time. The relevant principle lies in that two adjacent sequential images are captured by an auxiliary area-array CCD camera, these images are correlated by the

Ukr. J. Phys. Opt. 2018, Volume 19, Issue 1 
JTC, and the image shifts are calculated by measuring the distance between the correlation peaks. The authors of Ref. [6] have added a white noise with the variance ranging from 0 to 1.4 into the power spectrum and simulated the influence of detector noise in the spectral plane on the accuracy of optical correlation. Their results have shown that the JTC reveals good noise immunity and the measurement accuracy is affected insignificantly whenever the noise variance is less than 0.8 . On the other hand, the errors become progressively higher with further increasing variance, until the measurements fail. A pattern noise and a background noise have been introduced in the input images in Ref. [6], although their relation with defects of actual devices has not been considered.

One should realize that the signal-to-noise ratio (SNR) of the images taken by the auxiliary area-array CCDs is lower according to the operation principles of the space cameras, while the devices built basing on JTCs are also not perfect. The both effects would influence the accuracy of measuring the image shifts. Hence, it is necessary to study the influence of the pattern noise and the background noise on the accuracy. This problem seems to be important for assessing the validity of the JTC-based shift measurements and increasing the image quality for high-resolution space cameras.

In this work, we first explain the principles of the image-shift measurements based on the JTC. Then we introduce the white background noise and the pattern noise with different variance values into the input images of the JTC to study the influence of noise on the accuracy. Finally, we build the experimental platform and study comprehensively the noise immunity of the JTC.

\section{Principles of measuring the image shifts based on JTC}

A structural scheme of our optoelectronic JTC is displayed in Fig. 1. To make it simple and compact, we use the JTC consisting of a single lens and a spatial light modulator [Fan C, 2017. Ukr.J.Phys.Opt. 18: 55-65]. The reference image $r(x, y)$ and the target image $t(x, y)$ are displayed alongside in $y$ direction at the spatial light modulator, with their centres located at $(0, a)$ and $(0,-a)$. Compared with the reference image, the scene in the target one is moved some distances $\Delta x$ and $\Delta y$ along the $x$ and $y$ directions, respectively. Then the input of the JTC is as follows:

$$
E(x, y)=r(x, y-a)+t(x+\Delta x, y+a+\Delta y)
$$

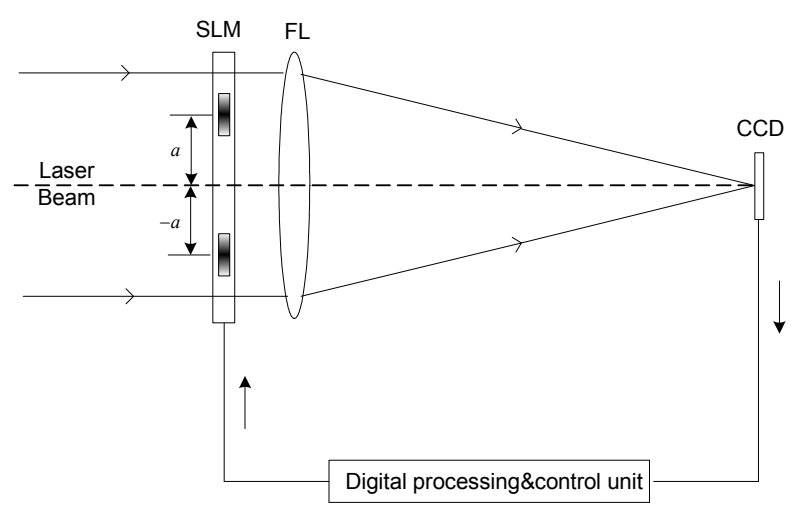

Fig. 1. Structural scheme of our optoelectronic JTC.

After transformation occurring in the Fourier lens, the joint spectrum $G(u, v)$ can be obtained in the Fourier plane:

$$
G(u, v)=R(u, v) \exp (-2 i \pi a v)+T(u, v) \exp \{2 i \pi[u \Delta x+(a+\Delta y) v]\},
$$

where $R(u, v)$ and $T(u, v)$ are the Fourier transforms of $r(x, y)$ and $t(x, y)$, respectively. There is a CCD camera in the Fourier plane, which records the intensity distribution given by 


$$
\begin{aligned}
|G(u, v)|^{2}= & \left.|R(u, v)|^{2}+|T(u, v)|^{2}+R(u, v) T^{*}(u, v) \exp \{-2 i \pi[u \Delta x+(2 a+\Delta y) v)]\right\} \\
& +T(u, v) R^{*}(u, v) \exp \{2 i \pi(u \Delta x+(2 a+\Delta y) v]\}
\end{aligned}
$$

where the superscript $*$ represents the complex conjugate. Controlled by digital processing and a control unit, the power spectrum $|G(u, v)|^{2}$ is reloaded to the spatial light modulator, thus replacing the input. Then it is transformed by the Fourier lens again, so that the complex amplitude distribution in the output plane of the optical system reads as

$$
\begin{aligned}
c(x, y)= & t(x, y) \otimes t(x, y)+r(x, y) \otimes r(x, y)+t(x, y) \otimes r(x, y) * \delta(x-\Delta x, y-2 a-\Delta y) \\
& +r(x, y) \otimes t(x, y) * \delta(x+\Delta x, y+2 a+\Delta y)
\end{aligned}
$$

where the symbols $*$ and $\otimes$ represent respectively convolution and correlation, and $\delta$ stands for the delta function. The first two terms in the r. h.s of Eq. (4) correspond to auto-correlations, and the last two ones are cross-correlations. According to Eq. (4), when the initial and shifted images contain the same information with slight shifts $\Delta x$ and $\Delta y$ only, then these shifts can be measured by finding the displacement between the actual cross-correlation peaks and their ideal points $(0, \pm 2 a)$.

\section{Simulations of noise immunity of the JTC}

To study the noise immunity of our JTC, we have used the images taken by a space camera Quickbirds 2 (the resolution of about $0.62 \mathrm{~m}$ ). First a sub-image with the size $128 \times 128 \mathrm{pel}^{2}$ is extracted, which is used as an original image. Then, some image shifts along the $x$ and $y$ directions are added using linear interpolation. In this way we obtain a shifted image, with the shifts equal to $\Delta x=1.8$ pel and $\Delta y=1.2$ pel. To increase the accuracy of our simulations, the original and shifted images are binned together in the two directions by the two adjacent pixels, according to the Shannon sampling theorem. The two down-sampled images with the resolutions reduced by a factor of two in both directions can be obtained in this manner. They are used as reference and target images of the JTC. Their sizes are $64 \times 64 \mathrm{pel}^{2}$, and the image shifts between the two images amount to 0.9 pel and 0.6 pel along the row and column directions, respectively (see Fig. 2).

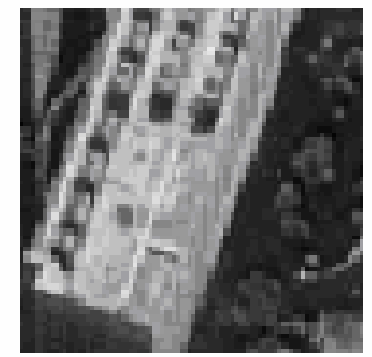

(a)

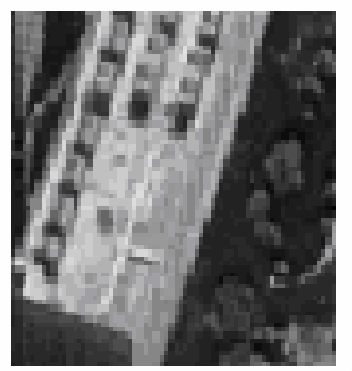

(b)

Fig. 2. Down-sampled images corresponding to (a) reference image and (b) target image.

Now the reference and target images should be loaded to the input JTC plane side by side, with their distance being equal to 160 pel. Due to the influence of strong auto-correlation peaks, the image shift cannot be measured accurately till the input image and the power spectrum of the JTC are not processed. A number of processing methods have been put forward by different researchers. These are binarization of the power spectrum, wavelet transform, Chirp modulation, fringe adjusting, amplitude modulation and others [7-10]. In principle, all of these methods can improve notably the performance of the JTC in pattern recognition. However, considering the 
accuracy and input-image variability requirements implied for the JTC that measures sub-pixel shifts, we have also tested and simulated some simple processing methods such as convolution, adding and subtraction (see Refs. [6, 11, 12]). Our results have demonstrated that the measurement accuracy can achieve a sub-pixel level, when the input images and the power spectrum are processed by the three methods mentioned above. The methods necessary for this aim include subtracting the power spectrum and its binarization with zero threshold (referred to as the method \#2), subtracting the power spectrum and its binarization with zero threshold after edge-enhancing the input image by convolution with $3 \times 3$ or $1 \times 3$ Laplace kernels (the methods \#1 and \#3, respectively). The results obtained using these three methods are listed in Table 1.

Table 1. Measurement errors manifested by different processing methods.

\begin{tabular}{cccc}
\hline Method & Processing of the input & $\begin{array}{c}\text { Processing of the } \\
\text { power spectrum }\end{array}$ & $\begin{array}{c}\text { Mean-squared } \\
\text { error, pel }\end{array}$ \\
\hline$\# 1$ & $\begin{array}{c}\text { Edge enhancing by convolution } \\
\text { with a } 3 \times 3 \text { Laplace kernel } \\
\text { None }\end{array}$ & $\begin{array}{c}\text { Subtracting and } \\
\text { binarization with } \\
\text { zero threshold }\end{array}$ & 0.109 \\
$\# 3$ & $\begin{array}{c}\text { Edge enhancing by convolution } \\
\text { with a } 1 \times 3 \text { Laplace kernel }\end{array}$ & 0.115 \\
\hline
\end{tabular}

\subsection{Influence of background noise on the measurement accuracy}

When the JTC functions in any real conditions, it is impossible to make the background totally dark. As a result, outside stray light, which represents a background noise, always influences the work of the JTC. At the same time, the constituent components of the JTC are also not ideal. For example, one can remind of scattering, spatial heterogeneity and surface errors associated with a spatial light modulator. Moreover, inherent defects of the latter can also contribute to the background noise.

It is difficult to analyze the influence of the background noise on image-shift measuring in any distinct way, since the exact distribution and the amplitude of the noise vary for different devices. To be simpler, we have added a white Gaussian noise with the variance equal to 10 in our simulations. For instance, let the power spectrum be subtracted and binarized with zero threshold after the input image has been edge-extracted by convoluting with the $3 \times 3$ Laplace kernel. Then the normalized power distribution of the correlation is given by Fig. 3. Twenty shifted images with different shifts have been obtained using the methods mentioned above, and the white background noise with the same variance has been added. After that, the image shifts have been measured using the three different processing methods listed in Table 1. The corresponding measurement errors are displayed in Table.2.

Table 2. Measurement errors manifested by different methods in case of the background noise.

\begin{tabular}{|c|c|c|c|}
\hline Method & Processing of the input & $\begin{array}{l}\text { Processing of the power } \\
\text { spectrum }\end{array}$ & $\begin{array}{c}\text { Mean-squared } \\
\text { error, pel }\end{array}$ \\
\hline$\# 1$ & $\begin{array}{c}\text { Edge enhancing by } \\
\text { convolution with a } 3 \times 3 \\
\text { Laplace kernel }\end{array}$ & \multirow{3}{*}{$\begin{array}{c}\text { Subtracting and } \\
\text { binarization with zero } \\
\text { threshold }\end{array}$} & 0.159 \\
\hline$\# 2$ & None & & 0.116 \\
\hline$\# 3$ & $\begin{array}{c}\text { Edge enhancing by } \\
\text { convolution with a } 1 \times 3 \\
\text { Laplace kernel }\end{array}$ & & 0.175 \\
\hline
\end{tabular}



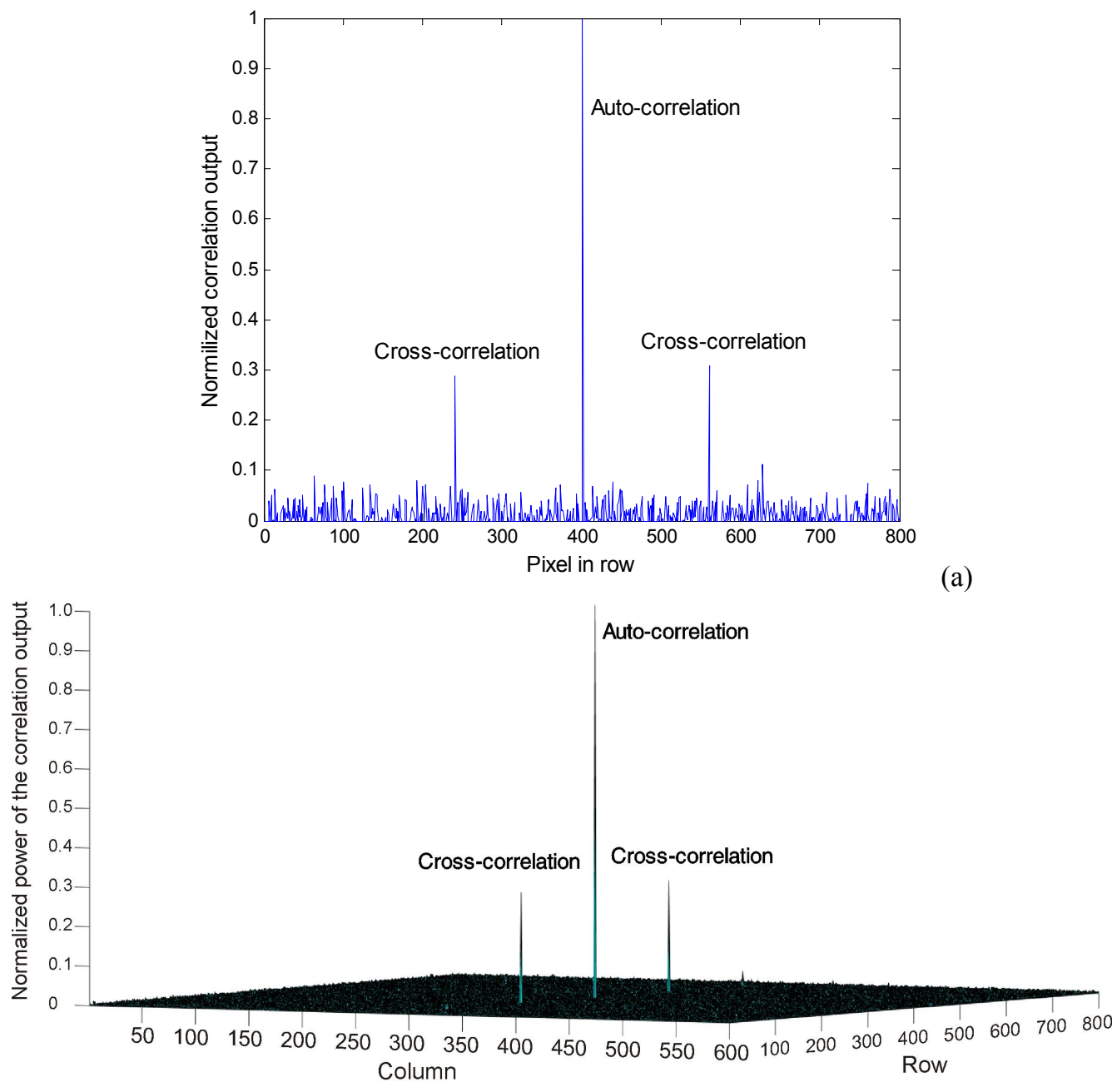

(b)

Fig. 3. Normalized outputs of our JTC: (a) power distribution of the correlation and (b) its two-dimensional plot.

A comparison of the data presented in Table 1 and Table 2 demonstrates that the measurement accuracy becomes lower when the background noise is added. This is especially appreciable for the methods $\# 1$ and \#3. The reason is that the intensity of the input image decreases significantly when the image is convoluted. For example, the mean grey level in the image of Fig. 2a is equal to 109.32, though it decreases down to 42.6 or 15.2 after the images are convoluted with the $3 \times 3$ or $1 \times 3$ Laplace kernels, respectively. As a consequence, the SNR decreases when the background noise with the same variance is added, thus reducing the accuracy for the image-shift measurements.

To solve this problem, the convoluted input images can be binarized with the threshold of zero, which makes the intensity of the processed images increase largely. As an example, the mean grey levels of the two convoluted images mentioned above are equal to 133.97 and 132.68 after binarization. This enhances the intensity of the input images efficiently.

To study the influence of the background noise on the measurement accuracy in more detail, we have added different white background noises to the input image, with the variances $\sigma$ equal to 20,30, 40 and 50. The corresponding measurement errors obtained for the cases of different processing methods are shown in Table 3. One can see that the accuracy for the image shifts 
decreases with increasing variance of the white noise. A comparison testifies that the processing becomes more sensitive to the background noise when the input images are convoluted according to the methods \#1 and \#3. Moreover, the measurement accuracy deteriorates seriously with increasing noise. However, the measurement accuracy becomes better when the input images are binarized with the zero threshold after being convoluted, as in case of the methods \#4 and \#5. Then the errors change less with increasing noise.

Table 3. Measurement errors manifested by different methods in case of different background noise levels.

\begin{tabular}{|c|c|c|c|c|c|c|}
\hline \multirow{2}{*}{ Method } & \multirow{2}{*}{$\begin{array}{l}\text { Processing in the input } \\
\text { plane }\end{array}$} & \multirow{2}{*}{$\begin{array}{l}\text { Processing of the } \\
\text { power spectrum }\end{array}$} & \multicolumn{4}{|c|}{ Mean-squared error, pel } \\
\hline & & & $\sigma=20$ & $\sigma=30$ & $\sigma=40$ & $\sigma=50$ \\
\hline$\# 1$ & $\begin{array}{l}\text { Edge enhancing by } \\
\text { convolution with a } 3 \times 3 \\
\text { Laplace kernel }\end{array}$ & & 0.188 & 0.224 & 0.280 & 0.357 \\
\hline \#2 & None & & 0.128 & 0.143 & 0.178 & 0.190 \\
\hline$\# 3$ & $\begin{array}{l}\text { Edge enhancing by } \\
\text { convolution with a } 1 \times 3\end{array}$ & & 0.208 & 0.259 & 0.302 & 0.402 \\
\hline \#4 & $\begin{array}{l}\text { Binarization with zero } \\
\text { threshold after edge } \\
\text { enhancing by } \\
\text { convolution with a } 3 \times 3 \\
\text { Laplace kernel }\end{array}$ & $\begin{array}{l}\text { Subtracting and } \\
\text { binarization with } \\
\text { zero threshold }\end{array}$ & 0.105 & 0.11 & 0.122 & 0.149 \\
\hline \#5 & $\begin{array}{l}\text { Binarization with zero } \\
\text { threshold after edge } \\
\text { enhancing by } \\
\text { convolution with a } 1 \times 3 \\
\text { Laplace kernel }\end{array}$ & & 0.109 & 0.115 & 0.127 & 0.157 \\
\hline
\end{tabular}

\subsection{Influence of pattern noise on the measurement accuracy}

According to the principles of measuring the image shifts, an area-array CCD is mounted in the focal plane of the space camera to catch the pictures which are used as input images for the JTC. Suppose that the height of the satellite is equal to $500 \mathrm{~km}$ and the focal length of the camera is $5 \mathrm{~m}$. Then the moving speed of the image in the focal plane can achieve $7 \times 10^{-2} \mathrm{~m} / \mathrm{s}$. To avoid a speed mismatch between image motion and travelling of the charge packet of CCD, the exposure time should be very short, thus inducing a lower SNR for the picture. At the same time, there is light scattering and absorption of atmospheric molecules and aerosols, which also decrease the SNR during short exposure times.

Basing on the above reasons, one has to measure the image shifts for the cases of images with low SNRs input to the JTC. In order to study the influence of the pattern noise on the measurement accuracy, we add the white Gaussian noise to make the SNR of the input images vary from 1 to $15 \mathrm{~dB}$. We have studied the measurement accuracy at different SNR levels, when the input-image sizes are equal to $32 \times 32,64 \times 64,96 \times 96$ and $128 \times 128 \mathrm{pel}^{2}$. The simulation results are shown in Fig. 4. 

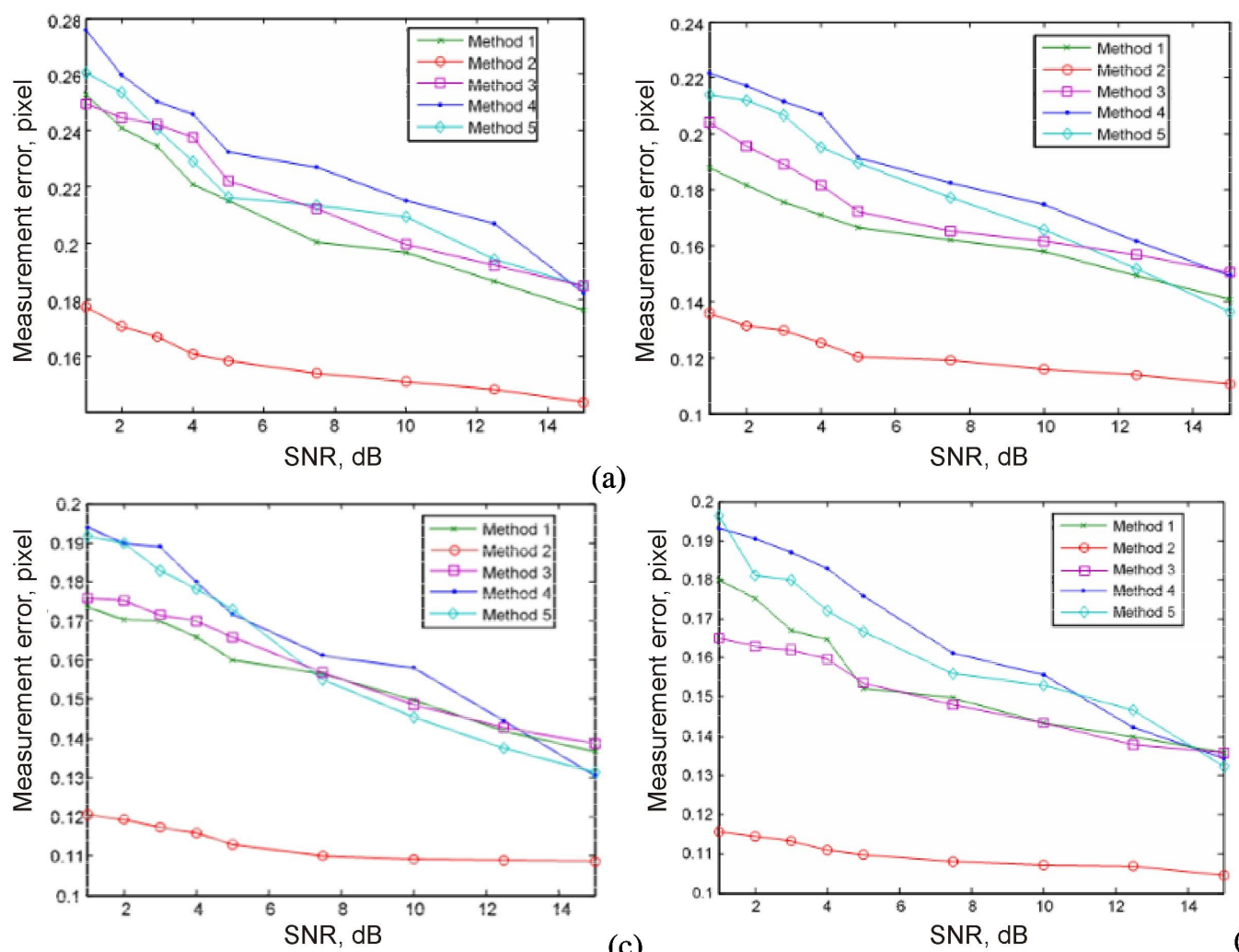

(d)

Fig. 4. Relationships between the measurement error and the input pattern noise for the cases of images with the sizes $32 \times 32$ (a), $64 \times 64$ (b), $96 \times 96$ (c) and $128 \times 128 \mathrm{pel}^{2}(\mathrm{~d})$.

Following from the data displayed in Fig. 4, one can draw the following conclusions:

(1) The measurement accuracy becomes lower when the SNR of the image decreases. Here the reason is that the correlation between the two input images of the JTC becomes lower with increasing noise. In its turn, this is because the distribution of the noise is random, which reduces the output power of the correlation peak of the JTC and so the measurement accuracy.

(2) The measurement accuracy is improving when the SNR of the input images remains the same and the size of the input image increases. This is because increasing image size provides stronger useful signals, thus implying stronger cross-correlation peaks and more accurate measurements.

(3) Among all of the five methods under our test, the methods \#1, \#3, \#4 and \#5 prove to be notably sensitive to the noise. This is especially true for the methods \#1 and \#4, the pattern-noise immunities of which are the worst. Compared with the other methods, the method \#2 reveals the best measurement accuracy, which also changes little with increasing noise.

\subsection{Comprehensive analysis of noise immunity of the JTC}

According to the above simulations, the measurement accuracy can be improved with increasing size of the input image, no matter which of the processing methods is used. However, increasing image size induces also larger amounts of necessary computations and affects the measurement speed seriously. Considering the above restriction, the image size $96 \times 96 \mathrm{pel}^{2}$ has been selected in our further simulations. Here one has to take into account that the exposure time of CCDs is very short, which induces much noise in the image. Because the noise cannot be easily avoided or 
controlled, we let the SNR of the image be equal to $1 \mathrm{~dB}$. On the other hand, the background noise can indeed be controlled with some methods (e.g., with a stray-light avoiding technology or photoelectric devices with good performance). Then the variance of the background noise can be selected as $\sigma=20$ in the simulations.

We have studied the measurement accuracy for the five processing methods in the case when both the pattern and background noises are added to the input images. It is easily seen from Table 4 that the results are more sensitive to the pattern noise when the input image is edge-extracted by convoluting with the Laplace kernel (the methods \#1, \#3, \#4 and \#5). This imposes higher measurement errors. When the power spectrum is only subtracted and binarized with the zero threshold, as in case of the method \#2, the measurement accuracy is the best and the mean-squared error remains less than $0.2 \mathrm{pel}$. At the same time, the input image under these conditions needs no further processing, which improves largely the real-time processing property.

Table 4. Measurement errors appearing when both the background and input image noises are added.

\begin{tabular}{cccc}
\hline Method & Processing in the input plane & $\begin{array}{c}\text { Processing of the power } \\
\text { spectrum }\end{array}$ & $\begin{array}{c}\text { Mean-squared } \\
\text { error, pel }\end{array}$ \\
\hline$\# 1$ & $\begin{array}{c}\text { Edge enhancing by convolution with a } \\
3 \times 3 \text { Laplace kernel } \\
\text { None }\end{array}$ & & 0.206 \\
$\# 3$ & $\begin{array}{c}\text { Edge enhancing by convolution with a } \\
1 \times 3 \text { Laplace kernel }\end{array}$ & $\begin{array}{c}\text { Subtracting and } \\
\text { binarization with zero } \\
\text { threshold }\end{array}$ & 0.142 \\
& $\begin{array}{c}\text { Binarization with zero threshold after } \\
\text { edge enhancing by convolution with a } \\
3 \times 3 \text { Laplace kernel }\end{array}$ & 0.213 \\
& $\begin{array}{c}\text { Binarization with zero threshold after } \\
\text { edge enhancing by convolution with a } \\
1 \times 3 \text { Laplace kernel }\end{array}$ & \\
\hline 55 & $\quad$ & 0.202 \\
\hline
\end{tabular}

\section{Experiments}

To verify the noise-immunity performance of our JTC for measuring the image shifts, we have built an experimental scheme shown in Fig. 5. Here an electrically addressed apparatus TFT-LCD XGA3 (Forth Dimension Displays Co Ltd, England) is used as a spatial light modulator. The corresponding spatial resolution is equal to $1024 \times 768 \mathrm{pel}^{2}$, the pixel pitch $18 \times 18 \mu \mathrm{m}^{2}$, and the pixel dimensions amount to $13 \mu \mathrm{m}(\mathrm{H}) \times 10 \mu \mathrm{m}(\mathrm{V})$. The CCD used in our experiments (EL-400ME, produced by DTA Co Ltd, Italy) has the resolution $768 \times 512$ pel $^{2}$ and the pixel dimensions $9 \times 9 \mu^{2}$. To match the aperture of the CCD with the size of a zero-order Fourier diffraction pattern of the pixelated spatial light modulator, we have calculated the focal length $f$ of the Fourier lens for the case of a He-Ne laser. It is equal to $f=196.6 \mathrm{~mm}$. According to the Fresnel diffraction conditions and the physical size of the spatial light modulator, a doublet lens has been selected as a Fourier lens. Its diameter is $30 \mathrm{~mm}$ and the relative aperture $1: 5.3$.

The reference image with the size $96 \times 96$ pel $^{2}$ has been obtained by linear interpolation and binning pixels. Then an image shift is added, resulting in a target image. After that, the white Gaussian noise is added into the two images, with the SNR taken to be $1 \mathrm{~dB}$. The both images are simultaneously loaded to the spatial light modulator, which produces the input images of the JTC. Resultant joint power spectrum, subtracted and binarized joint power spectrum, output of the 


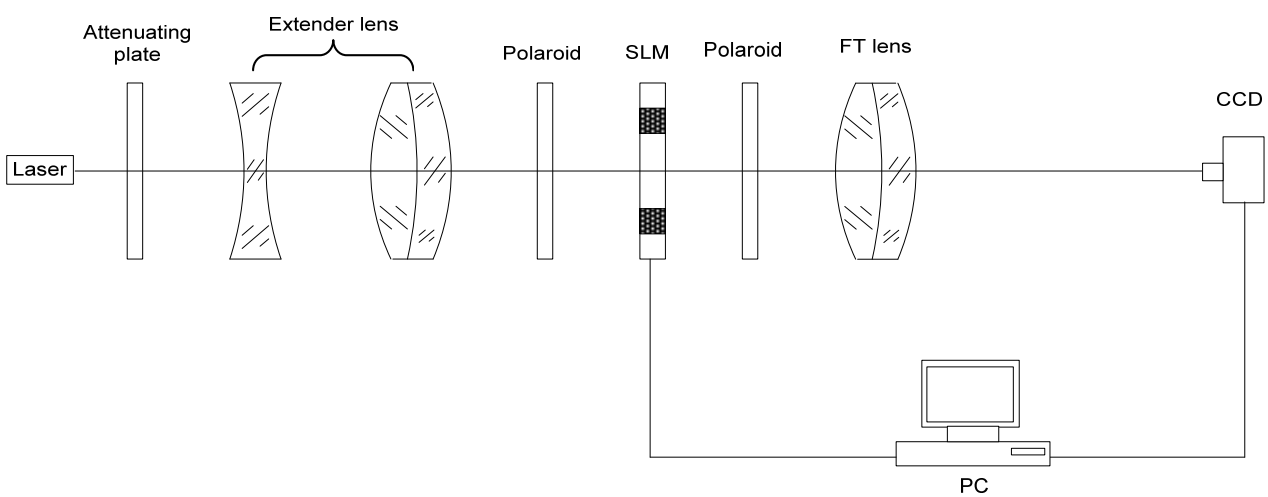

Fig. 5. General scheme of our JTC-based equipment for measuring image shifts.

correlation and normalized power distribution of the correlation peaks are shown in Fig. 6a-d, respectively.

100 sub-images have been extracted from different satellite images. They have been shifted, down-sampled and pixel-binned. We have added the pattern noises to the images, ensuring the SNR value equal to $1 \mathrm{~dB}$. The shifts between the reference and target images have been kept no larger than 60 pel. Finally, the image shifts have been measured using our JTC, and the measurement errors have been calculated and analyzed statistically. The results show that the distribution of the measurement errors is normal, with the mean-square deviation error being less than 0.12 pel under the significance level 0.05 . Notice that, in case of the input images with the size of $96 \times 96 \mathrm{pel}^{2}$ and the SNR value of $1 \mathrm{~dB}$, the results obtained using the methods \#1, \#3, \#4 and \#5 remain sensitive to the pattern noise. The relevant mean measurement errors of the image shifts exceed 0.3 pel.
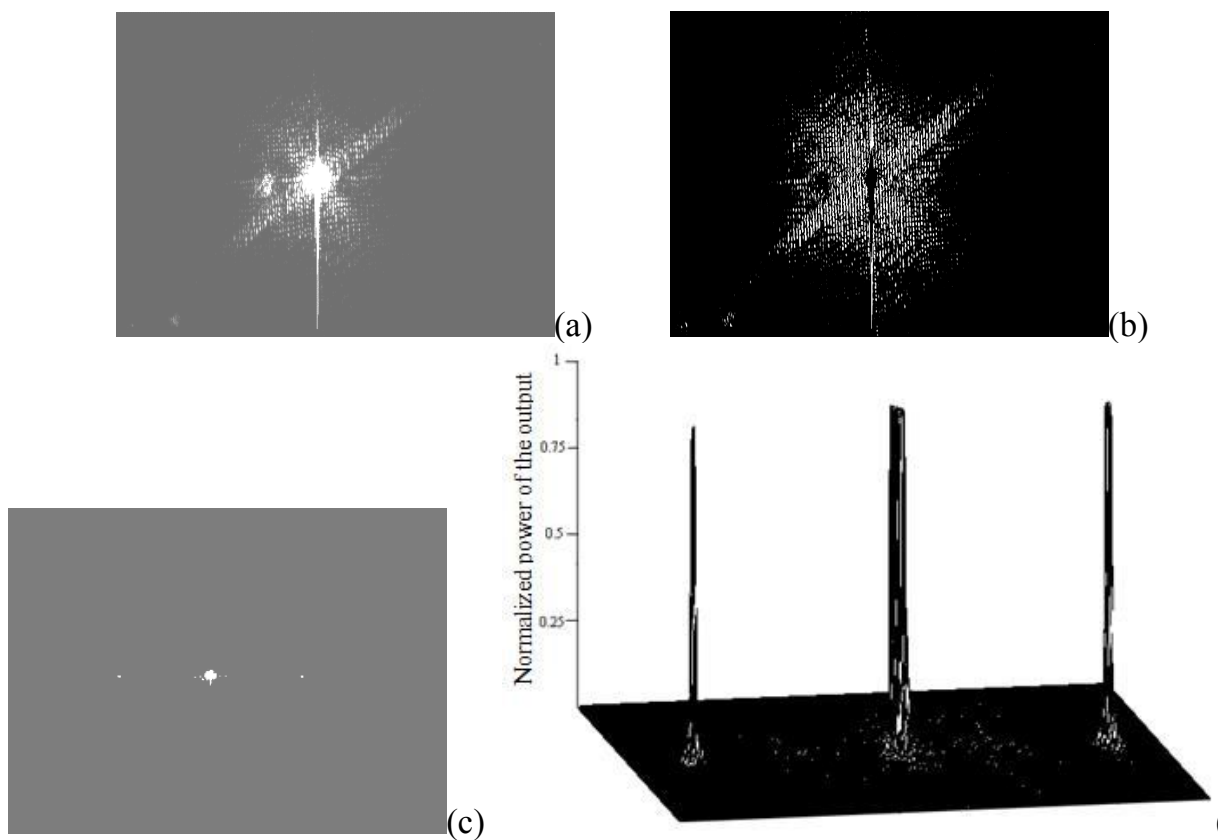

(d)

Fig. 6. Power spectra and correlations obtained for our JTC: (a) power spectrum, (b) subtracted and binarized power spectrum, (c) output of the JTC and (d) normalized power distribution of the output. 


\section{Conclusion}

In the present work we propose a JTC-based scheme for measuring small sub-image image shifts. According to our idea, the image shifts are measured with high enough accuracy, following from the data for the cross-correlation peak positions. A number of methods are used to compensate the shifts and improve the quality of images taken by space cameras. According to our simulation and experimental data, the sub-pixel shifts can be accurately measured with the JTC, whenever the power spectrum is subtracted and binarized with the zero threshold. Using this method, one obtains the errors for the image shifts less than 0.12 pel in case when the size of the input images reaches $96 \times 96 \mathrm{pel}^{2}$ and the SNR amounts to $1 \mathrm{~dB}$. Moreover, the measurement accuracy manifests almost no variations with increasing contents of the input-image and pattern noises.

Owing to these characteristics, our JTC-based technique for measuring the sub-image shifts is easy in use, accurate and high-speed. Moreover, the recent development of photoelectric devices and increasing data-transfer rates up to thousands frames per second for both the spatial light modulators and the CCD cameras make our JTC-based apparatus an attractive option for measuring the image shifts in real time.

\section{Acknowledgments}

This project is supported by the Key Laboratory of the Grain Information Processing and Control of the Ministry of Education of China (No KFJJ-2017-106), the Science and Technology Support Project of the State Grain Administration (No 201413001), the China Scholarship Council (No 201408410255), the Natural Science Foundation of Henan Province (No 162300410062), and the Rey Project of Science and Technology of Henan province (No 162102210198).

\section{References}

1. Zhu J B, Guo J and Li W J, 2016. An integral time calculation model for agile satellite TDICCD camera. Proceedings of IEEE 13th International Conference on Signal Processing (ICSP) 1736-1740.

2. Fan C, 2017. Research on the influence of the velocity-height ratio of a remote sensing camera on image quality. J. Opt. Technol. 84: 102-107.

3. Chao Fan, Hong-wei Yi, Yi-tao Liang, 2009. Influence analysis of the scroll on the image quality of the satellite camera. Proc. SPIE. 7384, International Symposium on Photoelectronic Detection and Imaging 2009: Advances in Imaging Detectors and Applications, 73840A.

4. Chiu C W, Chan P C and Wu D Y, 2007. Optimal design of magnetically actuated optical image stabilizer mechanism for cameras in mobile phones via genetic algorithm. IEEE Trans Mag. 43: 2582-2584.

5. Hyun Choi, Jong-Pil Kim, Myeong-Gyu Song, Wan-Chin Kim, No-Cheol Park, Young-Pil Park, and Kyoung-Su Park, 2008. Effects of motion of an imaging system and optical image stabilizer on the modulation transfer function. Opt. Express 16: 21132-21141.

6. Qi Li, Zhihai Xu, Huajun Feng, Peng Ge, Yueting Chen, Lianghui Li, 2010. Influence of noise on detection accuracy of joint transform optical correlator. Proc. SPIE 7850, Optoelectronic Imaging and Multimedia Technology, 78502M.

7. Kaewphaluk K and Widjaja J, 2017. Experimental demonstrations of noise-robustness of compression-based joint wavelet transform correlator in retinal recognition. Int. J. Light Electron Opt. 142: 168-173.

8. Isha M, Sudheesh K R and Naveen K N, 2014. Cryptanalysis of an image encryption scheme 
based on joint transform correlator with amplitude- and phase-truncation approach. Opt. Las. Eng. 52: 167-173.

9. Yixian Q, Xueting H Hua M, 2013. Improved target detection and recognition in complicated background with joint transform correlator. Optik. 124: 6282-6285.

10. Isabelle Leonard, Ayman Alfalou, Mohammad S. Alam, Andreas Arnold-Bos, 2012. Adaptive nonlinear fringe-adjusted joint transform correlator. Opt. Eng. 51: 098201.

11. Layton A and Marsh R, 2016. Object distance detection using a joint transform correlator. Proceedings of IEEE International Conference on Electro Information Technology (EIT). 707709.

12. Elbouz M, Alfalou A, Brosseau C, Ben Haj Yahia N, Alam MS, 2015. Assessing the perfomance of a motion tracking system based on optical joint transform correlation. Opt. Commun. 349: 65-82.

Fan Chao. 2018. Influence of noise on the accuracy of measuring image shifts based on optical correlator. Ukr.J.Phys.Opt. 19: 9 - 19.

Анотація. Запропоновано коррелятор із сумісним перетворенням (КСП) для вимірювання зрушень зображень, зроблених космічною камерою, із високою роздільною здатністю в режимі реального часу. Оскільки, відповідно до приниипів роботи, співвідношення сигнал/иум для вхідних КСП-зображень дуже низьке, необхідно вивчити вплив шумів на точність вимірювань зсуву. Спочатку ми пояснили принципи вимірювання зрушень зображень на основі КСП. Потім до вхідних КСП-зображень було додано білий фоновий таусовий шум $і$ структурний шум із різними величинами дисперсії. Було розраховано точність вимірювань зрушень для п'яти різних методів обробки. Побудовано експериментальну платформу для практичного впровадження намого підходу та вивчено ефективність вимірювань зрушень зображень за умов, коли фоновий і структурний шуми додаються. Результати симуляцій $і$ експериментальні дані свідчать, що точність вимірювань, притаманна методові віднімання енергетичного спектра та бінаризаиії з нульовим порогом, є вищою, порівняно з іншими чотирма розглянутими нами методами обробки. Зокрема, відповідна похибка вимірювання менша за 0,12 піксель навіть у разі вхідних зображень, що характеризуються співвідношенням сигнал-шум 1 дБ. Це досконало відповідає типовим робочим вимогам до космічних камер. 